\title{
Protagonismo do aluno e uso de metodologias ativas em prol da aprendizagem significativa e da educação humanista
}

Tatiane Alves Maciel-Barbosa ${ }^{1}$

Resumo: O presente artigo discorre acerca da necessidade de promover o protagonismo estudantil e a aplicação de metodologias ativas na Educação Básica por meio de projetos educativos mediados por tecnologia. Objetiva-se, com esta reflexão e estudo, utilizar recursos tecnológicos para proporcionar o desenvolvimento dos conceitos inerentes aos diferentes gêneros discursivos, a partir de sequências didáticas nas diferentes áreas do conhecimento, em prol da competência em leitura e escrita. Assim, faz-se necessário envolver princípios de metodologias ativas, como aulas invertidas e problematizações, em vista da concretização de uma aprendizagem significativa, inovadora, atualizada e humanista. Nesse sentido, urge a mudança de paradigmas no processo educativo, que deve estar alicerçado em leitura, problematização, debate, análise, escrita e publicações de textos de diferentes gêneros discursivos, consolidando o aluno como autor que transmite à sociedade suas ideias e reflexões em uma perspectiva interdisciplinar e de autonomia. Dessa forma, viabiliza-se a proficiência do estudante em leitura, escrita e tecnologias, favorecendo a efetiva aprendizagem e promovendo a educação humanista. Palavras-chave: Educação. Humanismo. Tecnologia. Protagonismo juvenil. Aprendizagem significativa.

\section{Student protagonism and use of active methodologies for significant learning and humanist education}

\begin{abstract}
This article discusses the need to promote student leadership and the application of active methodologies in basic education through educational projects mediated by technology. The purpose of this reflection and study is to use technological resources to provide the development of the concepts inherent to the different discursive genres, from didactic sequences in the different areas of knowledge, in favor of reading and writing skills. Thus, it is necessary to involve principles of active methodologies such as inverted classes and problematizations in view of the achievement of meaningful, innovative, up-to-date and humanistic learning. In this sense, it is urgent to change paradigms in the educational process, which should be based on reading, problematization, debate, analysis, writing and publications of texts of different discursive genres, consolidating the student as an author who transmits to society his ideas and reflections in a interdisciplinary
\end{abstract}


perspective and autonomy. In this way, the student's proficiency in reading, writing and technology is enabled, favoring effective learning and promoting humanistic education. Keywords: Education. Education. Humanism. Technology. Juvenile protagonism. Meaningful learning.

\section{Protagonismo del alumno y uso de metodologías activas en pro del aprendizaje significativo y de la educación humanista}

Resumen: El presente artículo discute la necesidad de promover el protagonismo estudiantil y la aplicación de metodologías activas en la educación básica a través de proyectos educativos mediados por tecnología. Se pretende, con esta reflexión y estudio, utilizar recursos tecnológicos para proporcionar el desarrollo de los conceptos inherentes a los diferentes géneros discursivos, a partir de secuencias didácticas en diversas áreas del conocimiento, en pro de competencia en lectura y escritura. Así, es necesario involucrar principios de metodologías activas como clases invertidas y problematizaciones para la concreción de un aprendizaje significativo, innovador, actualizado y humanista. En este sentido, urge cambiar paradigmas en el proceso educativo, que debe estar fundamentado en lectura, problematización, debate, análisis, escritura y publicaciones de textos de diferentes géneros discursivos, consolidando al alumno como autor que transmite a la sociedad sus ideas y reflexiones en una perspectiva interdisciplinaria y de autonomía. De esta forma, se viabiliza la competencia del estudiante en lectura, escritura y tecnologías, favoreciendo el efectivo aprendizaje y promoviendo una educación humanista.

Palabras clave: Educación. Humanismo. Tecnología. Protagonismo juvenil. Aprendizaje significativo.

\section{Introdução}

O presente artigo discorre acerca da necessidade de se promover protagonismo do aluno por meio da aplicação de metodologias ativas na Educação Básica em projetos educativos mediados por tecnologia.

Allan (2014), referindo-se ao panorama de Educação 3.0, apresenta o uso das tecnologias digitais em ambientes educativos para motivar a produção e a troca de conhecimentos e de alcance em espaços de conexões, criações, busca de soluções e de objetivos traçados.

Ademais, Carvalho Neto (2011), apontando os novos caminhos para uma educação que conduza o estudante a desvendar seus papéis sociais, evidencia também o desenvolvimento da capacidade dos alunos em solucionar problemas e atuar ativamente, entretanto agrega a necessidade de se pensar e agir nesses contextos de forma criativa, visto que o estudante é um sujeito produtivo em uma sociedade democrática e em constante transformação, ressaltando, conforme Carvalho Neto (2017a), uma prospectiva de Educação 4.0.

Nesse cenário, segundo Lévy (1999), deve-se usar o ciberespaço, emergido em uma cibercultura, a fim de se ampliarem linguagens, significações, variadas 
formas de utilização, veiculação e contextualizações de informações, acesso a conhecimentos e interações. Acredita-se, assim, que as atividades digitais, explorando inúmeros aplicativos de WebQuest, desafios, jogos, aplicativos de produções textuais, chats, fóruns, mapas conceituais, infográficos, entre outros recursos, viabilizam propostas educativas animadoras e motivacionais e transformam os ambientes educativos em espaços de construções em uma perspectiva intensa, dinâmica e entusiasmada.

Urge, então, a mudança de paradigmas no processo educativo, a qual deve estar alicerçada em aplicação de metodologias ativas, as quais, segundo Cyrino e Toralles-Pereira (2004), atuam como estratégias de ensino-aprendizagem com o objetivo de instigar o aluno a refletir, examinar, relacionar e investigar os problemas, relacionando-os a sua história e ressignificando suas evidências. Ainda conforme as autoras, nesses recursos ativos a problematização induz à construção do conhecimento a partir de um repertório amplo de alternativas, exercitando, nos estudantes, a liberdade e tomada de decisões em vista da concretização de uma aprendizagem significativa, inovadora, atualizada e humanista.

As estratégias pedagógicas de aprendizagem ativa são utilizadas com o propósito de conduzir o aluno a desvendar um caso e a compreender conceitos por si mesmo e, assim, levam esse estudante a relacionar suas descobertas com seu conhecimento prévio do mundo.

Dessa forma, o conhecimento em construção pelo aluno tem mais sentido do que aquele transmitido de forma passiva. O estudante é, então, o principal agente do processo de construção de seu conhecimento, agindo para aprender, e o professor tem o papel de facilitador e de orientador no processo de ensino e aprendizagem.

Nessa perspectiva, são propostos, atualmente, aos ambientes educativos inúmeros caminhos e projetos educativos delineados para promover o protagonismo do estudante em prol da aprendizagem significativa, partindo de sequências didáticas ${ }^{2}$ envolvendo uma série de estratégias, tais como leituras, pesquisas, problematizações, debates, análises, estudos de casos, grupos cooperativos e operativos, produções e publicações textuais de diferentes gêneros discursivos, consolidando o aluno como autor e produtor que transmite à sociedade suas ideias e reflexões em uma perspectiva interdisciplinar e de autonomia.

É oportuno ressaltar que o presente artigo, após discorrer acerca da Educação 3.0 e 4.0, do ciberespaço como ambiente educativo, das metodologias ativas, do protagonismo do aluno e das sequências didáticas, apresentará também uma exemplificação dessa proposta de aprendizagem ativa, mediada por tecnologias digitais, a partir de uma especificidade da área de língua portuguesa com gêneros discursivos, mas que deve ser aplicada em uma ótica interdisciplinar, como campo potencial de exercício do novo paradigma. 
Sendo assim, serão instigadas, nos espaços educativos, as produções e as criações interdisciplinares dos alunos por meio de diversos aplicativos e recursos, conforme os componentes curriculares da série do estudante. Também é proporcionada a possibilidade de conexões entre as temáticas sugeridas e oportunas em cada situação sociocomunicativa, além da viabilização do permanente diálogo acerca das diferentes áreas do conhecimento.

Verifica-se, assim, que propostas, por exemplo, de autoria e de produção de textos interdisciplinares dos alunos, abrangendo os mais variados gêneros discursivos, produzidas em diversas modalidades (orais, escritas e digitais), publicadas para um interlocutor real e amplo, em espaços virtuais, devem ser viabilizadas a fim de que os estudantes sintam-se sujeitos ativos e desenvolvam autonomia no processo ensino-aprendizagem, rompendo com a tradicional concepção de ensino em que se escrevem textos na escola para cumprir tarefa ou atribuir nota, tendo como destinatário somente o professor.

De acordo com Barbosa e Moura (2013), enquanto o professor atua como orientador, supervisor, facilitador do processo de aprendizagem, o aluno é o protagonista do processo. Assim, o desenvolvimento de atividades envolvendo o protagonismo juvenil e o uso de metodologias ativas em processos de leitura e escrita, a título de exemplificação, pode ser viabilizado, nessa direção, por meio de problematizações ou outras metodologias, como sugerem Cyrino e Toralles-Pereira (2004), em sequências didáticas, conforme orientam estudos de Dolz, Noverraz e Schneuwly (2004).

Tais proposições, mediadas pela utilização de recursos tecnológicos e das sequências didáticas, possibilitam o desenvolvimento dos conceitos inerentes aos diferentes gêneros discursivos e promove a proficiência da competência em leitura, escrita e uso de tecnologias, favorecendo a efetiva aprendizagem e promovendo a educação humanista. Segundo Garin (2003, p. 218):

O humanismo havia descoberto que o objetivo da educação era formar o homem, dar-lhe sua liberdade no mundo, torná-lo senhor do reino que Deus lhe havia concedido. Mas, precisamente a fim de não diminuir essa liberdade tão paradoxal, ele atribui à educação a missão de liberar o homem, de não o definir nem o coagir, de dar-lhe todo o poder em relação à consciência de si mesmo. Educar o homem é torná-lo consciente de si mesmo, de seu lugar no mundo e na história. O estudo dos antigos e de sua língua deveria justamente servir a esse fim: levar o homem, para além de qualquer definição, a se sentir senhor de si mesmo.

Em conformidade ao último documento da Congregação para a Educação Católica (2017), que aborda orientações para educar para o humanismo solidário em uma perspectiva de construção da civilização do amor, humanizar a educação significa considerar a pessoa no centro da educação, em um panorama de 
relações que constituem uma comunidade viva, interdependente, vinculada a um destino comum, educando para o humanismo solidário. Nesse sentido, visando a uma educação sólida e aberta, não se aceitam discriminações; promovem-se a riqueza e a diversidade dos talentos individuais e expande-se o perímetro da própria sala de aula a cada âmbito da experiência social em que a educação pode gerar solidariedade, partilha e comunhão.

Em suma, propostas educacionais dessa natureza são fundamentais e têm por propósitos expandir o aluno a refletir criativamente e, acima de tudo, favorecer para que ele alargue sua capacidade discursiva e saiba aplicá-la adequadamente às diferentes situações comunicativas, procedendo como cidadão ativo e participativo em uma sociedade democrática e em permanente evolução.

\section{Educação 3.0 e/ou Educação 4.0}

Promover o protagonismo do estudante com aplicação de metodologias ativas e projetos on-line na Educação Básica integra o modelo de Educação 3.0, o que, conforme Allan (2014), evidencia o desenvolvimento da capacidade dos alunos em solucionar problemas e atuar ativamente em uma sociedade libertadora e em permanente mudança.

Assim como se transformam os meios de produção e também o consumo, muda-se a maneira como se educam as crianças, os adolescentes, os jovens e os adultos. A fim de que os alunos se tornem capazes de circular ativamente na sociedade, de compreenderem e transformarem o mundo em que vivem, são necessárias mudanças de paradigmas na educação.

Nessa perspectiva, a sociedade deve inquietar-se pelo fato de que, nas últimas décadas, houve crescimento significativo da tecnologia e a consequente revolução do trabalho, no entanto a escola continua com poucas transformações, e falta aplicabilidade de metodologias ativas em prol do protagonismo estudantil.

Nesse sentido, a Educação 3.0 oportuniza as tecnologias digitais para a sala de aula, incentivando produções e troca de experiências em vistas à construção do conhecimento. Torna-se foco a interação, a partilha, o coletivo, e não os objetos técnicos, as plataformas e os aplicativos.

Dessa maneira, a sala de aula configura-se em espaço educativo onde os estudantes se conectam, criam, buscam soluções, enfrentam dificuldades, levantam hipóteses, constroem conhecimentos. Assim, em um ambiente de conexão e interação, acontece o processo de ensino e aprendizagem mediado por tecnologias digitais.

Conforme Barbosa e Moura (2013), o professor deixa de ser o detentor do saber e transfigura-se no docente da cultura digital, o qual orienta, incentiva, questiona, coordena, colabora em uma aprendizagem personalizada. A atuação 
docente ganha nova configuração, tendo em vista que esse professor passa a instigar, nos alunos, a tomada de decisões, o desenvolvimento de competências e habilidades diversas, a aprendizagem autônoma e investigativa, valorizando os conhecimentos prévios e as vivências dos estudantes.

Segundo Berbel (2011), as situações-problema, os estudos de caso, as problematizações, as aulas invertidas, entre outras estratégias, oportunizam investigação e compartilhamento de incertezas e revelações. A permanente partilha de experiências é primordial nesse contexto de Educação 3.0. Assim, as articulações são priorizadas, e a produção coletiva é viabilizada.

Carvalho Neto (2011, p. 17) afirma:

É altamente provável que mudanças que venham a se fazer sentir na Educação não estarão desatreladas de um amplo cenário mundial, contemporâneo, projetado num futuro de trinta a quarenta anos, o qual transcenderá as fronteiras nacionais e nacionalistas e se abrirá para a mundialização.

E ainda acrescenta:

A revaloração de aspectos cidadãos, a habilidade para aprender a aprender por toda a vida, os desafios de "aprender a ser", no contexto da diversidade humana e na gestão e autogestão de conflitos, as competências necessárias para o delineamento e o enfrentamento de problemas de toda natureza, o que em grande medida denota demandas por inovação e um outro sem número de expectativas sociais para os cidadãos podem estar afetando os vetores que constituem as bases de novos modelos educacionais (CARVALHO NETO, 2011, p. 18).

Nessa perspectiva, esse autor aponta a necessidade de uma educação voltada para novas configurações, na qual os sujeitos desvendam seus papéis sociais no processo educativo. Em recentes trabalhos, indica a necessidade de ter em vista propostas e planejamentos no modelo de Educação 4.0, no qual salienta o aluno, além de inserido nas possibilidades tecnológicas, também versado em artes, criatividade e filosofia. De acordo com esse autor:

Se antes, para a formação profissional, o valor de mercado estava no domínio da técnica, hoje o diferencial se situa no âmbito da cognição e esta mudança de paradigma implica uma profunda revisão quanto ao desenvolvimento de competências e habilidades (conhecimento tácito) e da gestão e produção de mídia (conhecimento explícito), no exercício das profissões. Os impactos gerados por esses novos cenários representam extraordinários desafios [...] e, portanto, para as instituições que se dedicam à educação e pesquisa neste segmento (CARVALHO NETO, 2017a, s/p). 
Nesse contexto educacional vigente e prospectivo, em que o professor atua como guia de um processo dirigido pelo próprio estudante, há constante colaboração entre colegas e docentes.

Assim, nesses modelos atuais de educação, é o aluno quem escolhe e seleciona os métodos de aprendizado, assim como os assuntos aos quais deseja se dedicar mais e os caminhos e meios para se alcançarem esses objetivos e metas traçados. E ainda desenvolve, conforme Carvalho Neto (2017a), sua capacidade de criar, representar, programar, ler, pintar, fotografar, cantar, filosofar, entre outras ações desse universo de protagonismo.

A educação almejada com protagonismo do aluno e com aplicação de metodologias ativas não pode ser entendida como aquela que apenas usa lousa eletrônica ou tablet para exclusivamente permanecer transmitindo o conhecimento. Ela é, primordialmente, a junção de quatro bases, em consonância aos pilares de educação de Delors et al. (2001), quais sejam: uma nova concepção do que ensinar, o que requer mudança de conteúdos; como ensinar, em uma perspectiva de novas metodologias; o que ensinar, a partir de recursos didáticos diversificados, principalmente tecnológicos; e, por fim, o que desenvolver, abordando as novas habilidades para entregar como resultado, ao final do processo educativo, um aluno ativo, protagonista, autônomo, criativo e produtor.

Assim, o sistema educacional, ao incorporar as novas tecnologias, que indiscutivelmente precisam fazer parte do universo escolar, deve estabelecer meios que não reafirmem nas escolas a robotização dos seres humanos. Sem dúvida, a escola deve ser espaço de pessoas, e não de máquinas.

\section{O ciberespaço como ambiente educativo}

Esse novo espaço que surge, denominado ciberespaço, desprende as fronteiras comunicacionais e engloba uma perspectiva permanente de percepções, descobertas, estruturações e desestruturações. Também oportuniza reflexões no horizonte de um processo educativo on-line.

Segundo Lévy (1999, p. 85):

A palavra "ciberespaço" foi inventada em 1984 por William Gibson em seu romance de ficção científica Neuromante. No livro, este termo designa o universo das redes digitais, descrito como campo de batalha entre as multinacionais, palco de conflitos mundiais, nova fronteira econômica e cultural. [...] Eu defino ciberespaço como o espaço de comunicação aberto pela interconexão mundial dos computadores e das memórias dos computadores. [...].

O ciberespaço compõe as mídias integradas. Integra um mundo ilimitado de informações, conectando o homem ao aparato tecnológico em uma associa- 
ção que, com a ausência de inteligência, de acordo com Lévy (1999), mutila a sua potencialidade. Percebe-se, nessa direção, o cuidado e a necessidade de orientação do professor em todo o processo de utilização das mídias digitais.

Vale ressaltar também que não há como ignorar a importância das Tecnologias da Informação e Comunicação (TICs) no âmbito escolar e deixar de usá-las, posto que a maioria dos alunos tem acesso à internet, e muitas escolas já utilizam materiais didáticos digitais ou ainda laboratórios de informática em um contexto educacional, em que os alunos, protagonistas do processo, são nativos digitais e usam, naturalmente, aparelhos tecnológicos no cotidiano.

Diante disso, é certo que muitos são os recursos e as possibilidades de uso dos meios eletrônicos e que os espaços virtuais permitem publicar textos, interagir, partilhar ideias e criações, além de propor reflexões sociais.

A respeito das vantagens do uso do ciberespaço, Lévy (1999, p. 93) faz a seguinte afirmação:

Este novo meio tem a vocação de colocar em sinergia e interfacear todos os dispositivos de criação de informação, de gravação, de comunicação e de simulação. A perspectiva da digitalização geral das informações provavelmente tornará o ciberespaço o principal canal de comunicação e suporte de memória da humanidade a partir do início do próximo século.

Em relação aos obstáculos para viabilizar propostas mediadas pela tecnologia em contextos educacionais, Sancho Gil et al. (2006) apresentam como uma dificuldade o fato de que, por muitos anos, a escola centrava o conhecimento no professor. Embora o docente ainda seja indispensável, sua função torna-se de mediador, orientador e facilitador da construção do conhecimento.

É fundamental aceitar que a escola não é mais a exclusiva fonte que os estudantes têm para adquirir dados e construir o conhecimento. Há as mídias incluídas nos processos educativos e que ampliam sua existência a cada dia de maneira mais exponencial.

De acordo com Gomes (2005), o professor depara-se com diferentes configurações de ensino, as quais integram tecnologia. Ao selecionar metodologias, recursos ou estratégias educativas, os docentes necessitam apropriar-se das novas tecnologias e explorá-las, visto que elas fazem parte da vida diária dos alunos e, acima de tudo, porque atraem e estimulam os protagonistas do processo educativo a aprender de maneira significativa.

O estudante tem verdadeira atração pelos recursos tecnológicos. Contudo, assim como muitos professores, tem dificuldade de visualizá-los como meios para a aprendizagem de novos conteúdos. Gomes (2005) afirma que os espaços virtuais podem ser considerados instrumentos de grande valia no âmbito escolar, porque 
possibilitam não só ao professor a disponibilização de materiais e informações, mas, a todos os envolvidos no processo, o acesso a inúmeras fontes e a socialização de produções, oportunizando postagens, produções, apreciações e considerações.

É válido ressaltar que esse dinamismo pode contribuir para a constituição de um aluno crítico e de um grande leitor virtual. Então, fazer uso do ciberespaço para socializar o trabalho do professor e do aluno democratiza o processo de ensino-aprendizagem e aproxima o trabalho realizado no interior da escola com a comunidade externa.

\section{Metodologias ativas e protagonismo juvenil: estratégias educacio- nais e o perfil do jovem na utilização das tecnologias para o seu desenvolvimento humano e acadêmico}

Este estudo direciona novas formas de planejar e executar propostas educativas inovadoras. Instiga-se uma perspectiva de educação em prol da aprendizagem significativa, em que o aluno é protagonista do processo, e o professor, o mediador.

A função da escola que se almeja, na atualidade, está diretamente ligada a ensinar a conhecer, formar para compreender, desenvolver o pensar para que alunos saibam lidar com as informações e estabelecer relações entre elas, sejam quais forem e, mais que isso, saibam escolher, decidir, projetar, agir e criar, uma vez que conhecem e relacionam o aprendido com a vida.

Nessa perspectiva, deve-se favorecer, na escola, conforme sugere Ausubel (apud MOREIRA; MASINI, 1982), a aprendizagem significativa, visto que todos são capazes de aprender, respeitando-se o tempo e as modalidades necessárias e sabendo envolver o estudante, de modo que ele se sinta responsável pela sua formação humana e acadêmica.

Urge promover e articular o ensino e a aprendizagem, o conteúdo e a forma de transmiti-lo, proporcionando, cada vez mais, ambientes educativos favoráveis à aprendizagem que faz sentido na vida do aprendiz, nos quais todas as ações proporcionem o processo múltiplo, complexo e relacional de conhecer e incorporar dados novos ao repertório de significados.

Deve-se considerar também que toda estruturação do ensino, planejamento, atividades, recursos e avaliações demandam dos educadores ações coerentes com as metas estabelecidas pelo planejamento. Isso implica organização e critérios a fim de que se conquiste verdadeiramente o espaço do conhecimento de natureza tanto científica quanto social e ética.

Além disso, essa concepção pedagógica em prol de uma aprendizagem significativa, a partir do protagonismo do aluno e mediada pelas metodologias ativas, visa à educação humanista, em que o processo baseia-se na ética, trans- 
parência, competência, criatividade, inovação e responsabilidade social, além de garantir uma visão mais fiel das idiossincrasias humanas ao promover a (re)humanização das relações de produção. Portanto, a educação humanística deve integrar todo e qualquer programa de incentivo ao desenvolvimento do potencial dos colaboradores no processo educativo.

Atualmente, a sociedade versátil e imediatista necessita de uma educação humanística, sob a ótica da ética e pautada em princípios que ultrapassam o conhecimento à luz do saber, do pensar e do julgar. Nesse sentido, deve-se promover uma educação que se efetua focada nos aspectos humanos, que são direcionados para a realidade da vida. A dimensão ética deve ser reestruturada a partir dos fundamentos educacionais. Nessa acepção, Freire (2003) considera que a educação é uma prática da emancipação. Diante disso, o indivíduo é compreendido e percebe-se como formador de cultura, além de se enxergar como sujeito, e não como objeto da aprendizagem. Segundo Freire (2003, p. 92), "não é no silêncio que os homens se fazem, mas nas palavras, no trabalho, na ação-reflexão".

Acredita-se ainda que a dimensão da liberdade atinja a leitura de mundo de cada professor e aluno e, por meio de trocas dialógicas, constroem-se novos conhecimentos sobre leitura, escrita e tecnologias. Assim, direciona-se do senso comum ao conhecimento científico em um percurso contínuo de partilhas, o que requer predisposição do sujeito.

Segundo Arroyo (2000), o mundo envolve cultura, valores, representações coletivas, normas, modelos de homem e de mulheres, de criança, de jovem ou de adulto. Desse modo, a educação possui responsabilidade na criação da sensibilidade social necessária para reorientar a humanidade.

Diante dessa ótica de educação voltada ao protagonismo e ao uso de metodologias ativas, é pertinente viabilizar projetos em que o estudante sentir-se-á ativo no processo e com autonomia para organizar atividades propostas, saber gerir tempo e prioridades, selecionar e fazer escolhas, propor soluções, utilizar recursos disponíveis, desenvolver métodos de estudos, elaborar dossiês, respeitar instruções e, sobretudo, autoavaliar-se constantemente.

De acordo com Bastos (2006), as metodologias ativas são processos de interação de conhecimento, estudos, pesquisas, análises e decisões a problematizações. Dessa forma, o professor torna-se facilitador ou mediador a fim de que o aluno pesquise, pense, julgue, decida como solucionará um problema ou atingirá os objetivos. De acordo com esse autor, a aprendizagem ativa é um processo que disponibiliza caminhos que desenvolvem a capacidade de análise de situações e contextos e a aptidão para busca de soluções adequadas a determinada configuração situacional. Bastos (2006, p. 10) afirma:

O conceito de metodologias ativas se define como um processo interativo de conhecimento, análise, estudos, pesquisas e decisões individuais ou coletivas, com a finalidade de encontrar soluções 
para um problema. O autor docente deve atuar como um facilitador para que o estudante faça pesquisa, reflita e decida por ele mesmo o que fazer para alcançar os objetivos.

Logo, conforme Abreu e Masetto (1990), os professores irão viabilizar as várias possibilidades de metodologias ativas, direcionando os alunos à aprendizagem para a autonomia e tendo em vista um indivíduo crítico. Segundo os autores, o domínio das estratégias é uma maneira de o professor selecionar e propor possibilidades, de acordo com sua criatividade, reflexão e experiência, a fim de alcançar os objetivos da aprendizagem.

Nesse sentido, o envolvimento e a participação do aluno em relação às aprendizagens, quer pelo entendimento, quer pela opção ou desejo dele, são exigências primordiais para possibilitar-lhe o exercício de sua autonomia e a liberdade na conquista de deliberações em diversas circunstâncias vivenciadas, as quais o instrumentam para seu desenvolvimento humano e acadêmico.

As possibilidades de metodologias ativas que levam o aluno à autonomia no processo educacional são muitas. "O conhecimento e o domínio das estratégias é uma ferramenta que o professor maneja de acordo com sua criatividade, sua reflexão e sua experiência, para alcançar os objetivos da aprendizagem" (ABREU; MASETTO, 1990, p. 45). Esses autores consideram diversas metodologias ativas, tais como problematizações, estudos de caso, projetos, grupos operatórios, cooperativos, pesquisas, simulações, confronto com situações reais, entre outras, que devem ser criadas e possibilitadas pelo professor de acordo com as necessidades e anseios dos alunos.

Diante disso, reitera-se a importância de propostas educativas atualizadas e arrojadas e que integrem variadas formas de analisar as situações, tendo em vista a postura ativa do aluno no processo de ensino e de aprendizagem. Tais possibilidades de análises, produções, sínteses, criações, leituras, pesquisas, debates, usos de tecnologias permitem ao educando tornar-se um cidadão crítico, autônomo, agente de sua história e da sociedade.

\section{Exemplificação com gêneros discursivos e em sequências didáticas como campo potencial de exercício do novo paradigma}

A partir da concepção do desenvolvimento humano sociointeracionista, apoiada no pensamento de Vygotsky (1989), a evolução da pessoa se dá na relação entre o ambiente e o ser biológico, nas trocas entre parceiros sociais e por meio de processos de interação e mediação.

Faz-se necessário entender o estudante como sujeito, inserido na sociedade, dotado de competências e habilidades, e tudo aquilo que ele é e que há de ser é fruto da relação dialética com o outro e com o ambiente em que vive. 
Além disso, o processo de ensino e de aprendizagem, fundamentado no processo sociointeracionista, envolve professor, aluno e sociedade. Essa concepção pedagógica possibilita que o conteúdo escolar seja contextualizado em situações práticas do uso das múltiplas linguagens e dos diferentes gêneros e tipologias textuais.

A título de exemplificação e incentivo ao desenvolvimento da competência leitora, circunscrita nas diversas áreas do conhecimento, ilustram-se, neste estudo, propostas mediadas por tecnologias e pelos gêneros discursivos em sequências didáticas.

O docente precisa instigar a circulação de diferentes gêneros discursivos no contexto escolar e além dele, a partir de pesquisas on-line, debates, métodos de caso, projetos, aulas invertidas e problematizações em suportes temáticos abordados, como: crônicas, contos, fábulas, relatos, biografia, anedotas, tiras, infográficos, cordel, anúncio publicitário, músicas, poemas, artigos de opinião, cartas, certificados, editoriais, gráficos, jogos, entre outros.

Salienta-se que, em cada proposta de gênero discursivo apresentada aos alunos em diversos sites, blogs, bibliotecas on-line ou páginas de autores específicos, um conjunto de atividades, fundamentado nos objetivos de competência leitora, deve ser elaborado criteriosamente a fim de que o aluno amplie sua capacidade analítica do texto.

Tais atividades interativas oportunizam exercícios de compreensão, interpretação, debate e proposta de produção textual em uma perspectiva criativa, dinâmica, instigadora e estimulante. Pode-se entender, assim, que as práticas da linguagem, as quais envolvem debates, leituras, pesquisas e produções textuais como fenômeno de interlocução real, permeiam todas as áreas do agir humano, potencializando, na escola, a perspectiva interdisciplinar e de autonomia, ou seja, de protagonismo do estudante no processo educativo.

Partindo do pressuposto de que atividades aleatórias ou propostas eventuais tradicionais não asseguram o domínio de leitura e de escrita nem a inserção do aluno de forma motivadora e entusiasmada, faz-se necessária, nas escolas, a promoção de propostas envolvendo recursos tecnológicos e projetos dinâmicos com publicações em plataformas digitais de textos dos alunos como contribuição significativa para o aperfeiçoamento da capacidade linguística dos protagonistas do processo educativo, uma vez que, nesse viés, realizam-se ações estimulantes, práticas participativas e reflexivas no ato de redigir, debater e criar, enfim, de participar efetivamente e com satisfação.

Em relação à exemplificação, neste presente estudo, voltada a produções textuais, pode-se afirmar que é por meio da linguagem que o ser humano se legitima, interage e troca experiências. Também interpreta a realidade em que está inserido e a sua função enquanto integrante da sociedade. 
As Diretrizes Curriculares do Estado do Paraná (PARANÁ, 2006, p. 52) consideram a definição de gênero de Bakhtin (1992) apropriada, “[...] compreendendo a mobilidade, a dinâmica, a fluidez, a imprecisão da linguagem, não aprisiona os textos em determinadas propriedades formais".

Ao revelar a importância da existência dos gêneros e da sua apropriação enquanto mecanismo de socialização, as teorias de Bakhtin (1997) se apresentam essenciais na fundamentação de um modelo didático de gênero quando se propõe a tornar o aluno apto diante das exigências comunicativas do mundo contemporâneo.

Conforme estudos de Dolz, Noverraz e Schneuwly (2004), as sequências didáticas consistem em um aglomerado de atividades organizadas em torno de um gênero, possibilitando ao estudante depreender melhor a peculiaridade e a aplicabilidade desse gênero, assim como adequar seu discurso e linguagem às diferentes situações de comunicação orais e escritas.

$\mathrm{Na}$ atualidade, demandam-se níveis de leitura e de escrita diferentes dos que atenderam às exigências escolares tempos atrás. Assim, de acordo com as Matrizes de Referência de Língua Portuguesa e os Parâmetros Curriculares Nacionais (PCNs), para que o educando tenha competência leitora, ele deve ser capaz de uma série de habilidades, tais como: reconhecer tema do texto, diferenciar fato de opinião, detectar dados explícitos em um texto, depreender o sentido de uma palavra ou expressão, inferir uma informação implícita em um texto, analisar texto com apoio de material gráfico, reconhecer o objetivo de textos de diferentes gêneros, confrontar textos do mesmo tema, determinar causa/consequência entre partes do texto, caracterizar repetições e substituições que auxiliam para continuidade do texto, diferenciar posições distintas diante do mesmo tema, identificar tese, indicar relação entre tese e argumentos, distinguir partes primárias de secundárias, localizar conflito gerador, apontar marcas linguísticas nos textos etc. (BRASIL, 1998b).

Ao desenvolver a capacidade leitora mediante essas habilidades descritas, que são imprescindíveis a todas as áreas do conhecimento, o indivíduo torna-se apto a ultrapassar a simples leitura do texto, apreendendo outras linguagens além da escrita e que são primordiais ao entendimento do discurso.

A linguagem é concebida como um mecanismo dialógico com o qual a pessoa institui comunicabilidade, estabelecendo ou não significados em um labirinto de relações sociais.

Reitera-se, então, a ideia de que é por meio da linguagem que os sujeitos se comunicam. Assim, esta assume um caráter sociointeracionista, conforme os Parâmetros Curriculares Nacionais de Língua Portuguesa afirmam: “O princípio anula qualquer pressuposto que tenta referendar o estudo de uma língua isolada do ato interlocutivo" (BRASIL, 2000, p. 18). 
Nessa direção, conforme as Diretrizes Curriculares do Estado do Paraná (2006, p. 20) corrobora:

Pensar o ensino da língua portuguesa e da literatura implica pensar também as diferenças e contradições do quadro complexo da contemporaneidade. A rapidez das mudanças ocorridas no meio social e as inúmeras relações de poder presentes nas teias discursivas, que atravessam o campo social, constituindo-o e ao mesmo tempo sendo por ele constituídas, requerem do professor uma percepção crítica cujo horizonte é a mudança de posicionamento em sua ação pedagógica.

Deve-se considerar, segundo Soares (1999), a necessidade de ensinar e aprender as práticas sociais de leitura e de escrita. Nessa perspectiva, um grupo social ou um indivíduo apropriam-se da escrita e de suas práticas sociais com domínio, funcionalidade e originalidade. Um indivíduo alfabetizado não é necessariamente um indivíduo letrado, pois ser letrado implica usar socialmente a leitura e a escrita e responder às demandas sociais envolvendo tais competências e habilidades.

Ademais, Marcuschi (2005) apresenta que a leitura e a interpretação textuais devem ser trabalhadas em práticas pedagógicas que instiguem o aluno a apropriar-se das articulações da linguagem e a compreender que o discurso é fundamentalmente um fenômeno sociocultural, o qual associa a organização do mundo à constituição da própria vida dos cidadãos.

As Diretrizes Curriculares Nacionais (BRASIL, 1998c, 1998d) também assumem uma concepção de linguagem que estabelece o discurso como prática social, por isso é importante que não só nas aulas de Língua Portuguesa, mas também dos demais componentes curriculares, os educandos devam analisar e produzir diferentes gêneros discursivos. Nesse sentido, todo professor deve planejar e executar um programa de leitura, debate e escrita, conforme Kleiman (2001, p. 51), "[...] que permita ao aluno entrar em contato com um universo textual amplo e diversificado".

A dialogicidade entre leitor e texto se constitui à medida que a prática de leitura se realiza, assegurando a ampliação de experiências. Por meio da leitura e da escrita, então, o aluno torna-se um cidadão linguisticamente proficiente, capaz de compreender-se no mundo e assimilar as relações humanas e sociais. Nesse sentido, em todos os espaços educativos, devem-se oportunizar aos alunos a leitura e a escrita de diferentes gêneros textuais.

Nessa direção, torna-se imprescindível ao aluno entender que, nos tipos textuais denominados narração, argumentação, descrição, injunção e exposição, integra uma multiplicidade de gêneros, consequência das relações sociais, para que ele possa ser capaz de adequar sua linguagem, tanto oral como escrita, às características peculiares de cada situação comunicativa. Marcuschi (2008, p. 154155) esclarece acerca dessa diferenciação de tipos e gêneros textuais: 
Tipo textual designa uma espécie de construção teórica \{em geral uma sequência subjacente aos textos $\}$ definida pela natureza linguística de sua composição \{aspectos lexicais, sintáticos, tempos verbais, relações lógicas, estilo\}. O tipo caracteriza-se muito mais como sequências linguísticas (sequências retóricas) do que como textos materializados; a rigor, são modos textuais. Em geral, os tipos textuais abrangem cerca de meia dúzia de categorias conhecidas como: narração, argumentação, exposição, descrição, injunção. O conjunto de categorias para designar tipos textuais é limitado e sem tendência a aumentar. Quando predomina um modo num dado texto concreto, dizemos que esse é um texto argumentativo ou narrativo ou expositivo ou descritivo ou injuntivo.

Gênero textual refere os textos materializados em situações comunicativas recorrentes. Os gêneros textuais são os textos que encontramos em nossa vida diária e que apresentam padrões sociocomunicativos característicos definidos por composições funcionais, objetivos enunciativos e estilos concretamente realizados na integração de forças históricas, sociais, institucionais e técnicas. Em contraposição aos tipos, os gêneros são entidades empíricas em situações comunicativas e se expressam em designações diversas, constituindo em princípio listagens abertas [...]. Como tal, os gêneros são formas textuais escritas ou orais bastante estáveis, histórica e socialmente situadas.

De acordo com Lopes-Rossi (2002), é por meio do domínio do funcionamento da linguagem em situações de comunicação que os alunos se tornam autônomos no processo de produção escrita. Assim, uma vez que os gêneros discursivos são o meio pelo qual as práticas de linguagem se incorporam às atividades dos alunos, torna-se indispensável o entendimento da importância da transição do ensino fundamentado nas tipologias textuais para dar lugar aos gêneros textuais.

Faz-se necessário evidenciar que os tipos textuais são constructos teóricos, determinados por propriedades linguísticas inerentes que constituem sequências no interior dos gêneros textuais. De forma distinta aos gêneros, os tipos, ou tipologias textuais, não compõem uma lista aberta, mas abarcam um número limitado de construções teóricas, definidas pela natureza retórica dos textos. São formas de organização do discurso que não compreendem práticas sociodiscursivas, já que não se realizam, como afirma Lopes-Rossi (2002), como modelos típicos de enunciados usados em situações reais de comunicação.

Quanto à produção de textos e ao uso do ciberespaço para a socialização dessas criações, deve-se atentar à necessidade de planejamento e organização. Percebe-se, de maneira geral, que ainda não está presente nos alunos a cultura do planejar, do produzir, do refazer e do socializar.

Segundo Antunes (2003), devem-se criar, com os alunos, a prática do planejamento, o hábito do rascunho, o cuidado com as revisões, de modo que a primeira versão dos textos tenha sempre um caráter de produção provisória, e 
os alunos possam vivenciar, como prática natural, a experiência de fazer e refazer seus textos ou outras produções tantas vezes forem necessárias, assim como fazem aqueles que se preocupam com a qualidade do que escrevem.

Assim, nas aulas de Língua Portuguesa, e nas de outros componentes curriculares, por meio de aplicativos, chats, fóruns, diálogos virtuais, devem ser propostas constantemente situações de interlocução que fomentarão atividades não só de produção, mas também de reflexão, debates, análise, escrita e reescrita, reformulações.

Percebe-se que as produções e criações do aluno, quando incentivadas a ser escritas e publicadas no ciberespaço, estarão expostas a apreciações da comunidade educativa e da sociedade, o que fará aumentar a preocupação e a responsabilidade do aluno-autor diante da autenticidade e da organização do texto, o que contribui significativamente para a evolução da competência em leitura e escrita desse estudante.

Oportunizar esse desenvolvimento por meio de atividades e sequências didáticas mediadas pela tecnologia traz ao aluno maior envolvimento e motivação, uma vez que, segundo Rocha e Lemos (2014), a inserção contextualizada das metodologias ativas em um planejamento didático, estimulando entre docentes e discentes a criação cultural, o desenvolvimento do espírito científico e do pensamento científico, de forma equilibrada, propicia a aprendizagem significativa.

Além disso, a mescla entre sala de aula e ambientes virtuais é primordial para oportunizar a abertura da escola para o mundo e, assim, transportar o mundo para dentro da escola. Ademais, as redes sociais, nas quais há uma linguagem mais familiar, uma espontaneidade maior, uma fluência de imagens, ideias e vídeos, favorecem a aprendizagem significativa.

Verificam-se instituições educacionais inovadoras que já reconfiguraram aulas, projetos, espaços físicos e metodologias, fundamentados em atividades, desafios, problemas e jogos, em que cada aluno aprende no seu próprio ritmo e de acordo com suas necessidades e limites. E essa aprendizagem ocorre em colaboração e partilha com outros colegas, ou ainda em grupos e projetos cooperativos, com mediação de professores orientadores e com suportes e recursos diversificados.

Desse modo, à luz das metodologias ativas de aprendizagem, o aprendizado ocorre por meio da resolução de problemas a partir de situações reais. Dessa forma, professores, na sua disciplina, podem elaborar com os alunos projetos que integrem os principais assuntos da matéria e que utilizem pesquisa, entrevistas, narrativas, vídeos, jogos etc.

É fundamental que projetos em prol de uma educação diferenciada e de excelência estejam ligados à vida dos alunos de acordo com suas motivações. Para tal, o professor deve gerenciar as propostas, intermediando com os alunos as melhores formas de realizar o projeto, valorizando cada etapa e, principalmente, viabilizando a apresentação e a publicação da culminância do trabalho em um lugar virtual visível. 
Por conseguinte, a conciliação de aprendizagem por desafios, problemas reais, vídeos, jogos, links extras, animações, aplicativos, aula invertida, grupos cooperativos, problematizações, entre outros meios, é relevante a fim de que os alunos aprendam realizando algo efetivamente, aprendam juntos cooperativamente e ainda no seu próprio ritmo.

Indubitavelmente, jogos e aulas roteirizadas estão mais presentes nos ambientes educativos atuais. Essa geração é habituada a jogar, a usar aparelhos tecnológicos, a descobrir no imediato, a partilhar informações. Dessa maneira, essas propostas inovadoras de metodologias ativas facilitam a aprendizagem e favorecem o interesse e a participação dos alunos.

Diante disso, corrobora-se a pertinência de propostas interdisciplinares com foco em gêneros discursivos por meio de tecnologias, explorando leitura, debate, compreensão, interpretação e produção textuais de forma prazerosa e significativa, além de publicação de projetos criados pelos alunos em ambientes virtuais. Vale salientar também que essa abordagem visa desmistificar a ideia de que criações e textos produzidos na escola só servem para ser submetidos à apreciação do professor ou para aquisição de nota.

Reitera-se, então, que a criação e aplicação de projetos pedagógicos inovadores e o uso de metodologias ativas agregam, na organização curricular, a comunicação pessoal e a colaborativa, bem como a presencial e a on-line, possibilitando significativamente a aprendizagem.

\section{Aprendizagem significativa e interdisciplinaridade}

Aspectos a serem considerados pelas instituições escolares em prol da realização de propostas tecnológicas e humanistas devem ser aliados à concepção da promoção aos projetos educativos de excelência que contemplem: currículo, gestão eficiente, metodologias ativas, ambientes físicos e digitais envolventes, professores capacitados, visão e ação na perspectiva de alunos protagonistas e busca por uma aprendizagem legítima em uma abordagem interdisciplinar.

Segundo Ausubel (apud MOREIRA; MASINI, 1982), é indispensável, para que haja uma aprendizagem significativa, a predisposição dos alunos em aprender de forma profunda, e não superficialmente. De acordo com estudos desse autor, a aprendizagem superficial ocorre quando a intenção se limita a preencher os requisitos da tarefa. Assim, mais importante do que a compreensão do conteúdo, é prever o tipo de perguntas que possam ser formuladas sobre ele, aquilo que o professor julgará importante, o que gera memorizações, foco em testes, imposições.

Ainda conforme esse autor, a aprendizagem profunda, ao contrário, caracteriza-se pelo interesse dos alunos em entender o significado do que estudam, relacionando aprendizagens anteriores às experiências pessoais. Esse tipo de aprendizagem leva os alunos a avaliar o que vai sendo realizado e a perseverar até conseguirem um 
grau aceitável de compreensão sobre o assunto. E torna-se real quando há a intenção de compreender o conteúdo e, por isso, há forte interação do aluno com o assunto por meio do constante exame da lógica dos argumentos apresentados.

Nessa perspectiva de busca por uma aprendizagem profunda, organizam-se os elementos constitutivos da situação de ensino de forma motivante e desafiadora e deve-se cuidar da relação pessoal com os alunos a fim de que ela possa ser suporte para a ativação no universo deles, o que favorece um panorama favorável à vontade de aprender significativamente.

Os alunos ficarão dispostos e motivados a, constantemente, buscar diversas fontes e links em prol de uma proposta apresentada, ler textos de variados gêneros em meios digitais, debater e analisar esses suportes selecionados, redigir acerca de temáticas elencadas, em uma perspectiva autoral, criativa, autônoma e colaborativa.

Essa abordagem de ensino e aprendizagem, além de enriquecer o processo educativo e tornar o aluno um leitor mais competente, configura-se também em uma oportunidade de junção de temáticas e conteúdos discutidos na série em um mesmo período, proporcionando, assim, a interdisciplinaridade na escola.

A respeito de interdisciplinaridade, pode-se afirmar que esse termo aparece nos PCNs de Língua Portuguesa do Ensino Fundamental (BRASIL, 1998b). Essa ocorrência encaminha aos temas transversais e às articulações passíveis de serem estabelecidas por essa disciplina:

Os temas transversais abrem a possibilidade de um trabalho integrado de várias áreas. Não é o caso de, como muitas vezes ocorre em projetos interdisciplinares, atribuir à Língua Portuguesa o valor meramente instrumental de ler, produzir, revisar e corrigir textos, enquanto outras áreas se ocupam do tratamento dos conteúdos. Adotar tal concepção é postular a neutralidade da linguagem, o que é incompatível com os princípios que norteiam estes parâmetros. Um texto produzido é sempre produzido a partir de determinado lugar, marcado por suas condições de produção. Não há como separar o sujeito, a história e o mundo das práticas de linguagem. Compreender um texto é buscar as marcas do enunciador projetadas nesse texto, é reconhecer a maneira singular de como se constrói uma representação a respeito do mundo e da história, é relacionar o texto a outros textos que traduzem outras vozes, outros lugares. Dada a importância da linguagem na mediação do conhecimento, é atribuição de todas as áreas, e não só da de Língua Portuguesa, o trabalho com a escrita e a oralidade do aluno no que for essencial ao tratamento dos conteúdos (BRASIL, 1998b, p. 40-41).

Uma das opções a ser adotada pelo professor é o projeto educativo em uma perspectiva interdisciplinar, abrangendo as várias disciplinas que compõem o currículo escolar, revelando aos alunos que não existem limites entre as disciplinas, mas que uma desdobra-se na outra, complementando-a. Segundo Câmara (1999, p. 15): 
[...] a interdisciplinaridade deve ser pensada como entre ciências, por um lado, considerando o território de cada uma delas e, ao mesmo tempo, identificando possíveis áreas que possam se entrecruzar, buscando as conexões possíveis. E essa busca se realiza por meio de um processo dialógico que permite novas interpretações, mudança de visão, avaliação crítica de pressupostos, um aprender com o outro, uma nova reorganização do pensar e do fazer.

Essa ideia permite pensar que a interdisciplinaridade é uma atividade de restauração do princípio de singularidade do conhecimento humano, o qual, com a evolução científica, foi se dividindo e especificando de tal maneira que os componentes parecem não estar mais conectados ao todo. Assim, os docentes têm um papel essencial em desatar essa tradição alienante e ascender essa contradição existente entre a realidade e o saber.

Santos (2015) discorre sobre interdisciplinaridade e metodologias ativas. Consoante o autor, o princípio didático básico das metodologias ativas, a busca de solução para um problema, demanda trabalho cooperativo entre conteúdos de várias áreas do conhecimento, portanto uma abordagem interdisciplinar. Ao privilegiar a interdisciplinaridade, essas metodologias combatem uma formação reducionista e baseada na fragmentação do conhecimento.

Acredita-se que projetos que trabalhem, por exemplo, com os gêneros textuais ou discursivos e a publicação de textos em meios digitais, favorecendo a aprendizagem significativa e a interdisciplinaridade, são propostas eficazes para a construção do sujeito crítico, além da maior possibilidade de envolvimento e participação de alunos e, por consequência, um provável aumento no índice de alunos leitores, falantes e escritores proficientes.

Assim, são fundamentais práticas de educação humanista que enfatizem as relações interpessoais e o crescimento que desta resulta, além de que elas promovem o desenvolvimento da personalidade do indivíduo, dos seus processos e a organização pessoal da realidade na capacidade de o sujeito atuar como uma pessoa integrada.

\section{Promoção de propostas pedagógicas humanistas}

Freire (2003) enfatiza pontos primordiais do humanismo quando se refere a uma proposta de práticas necessárias à educação que desenvolva a autonomia do educando e sua insubmissão. Segundo esse autor e educador, aspectos da educação humanista deveriam ser utilizados pelos professores em busca de um processo de ensino para a liberdade, em prol da libertação e superação das estruturas impostas e conhecimentos preestabelecidos.

Segundo Mizukami (1986), o professor em si não transmite conteúdo, mas dá assistência, sendo facilitador da aprendizagem. O conteúdo advém das pró- 
prias experiências dos alunos. A atividade é considerada um processo natural que se realiza por meio da interação com o meio. Conforme a autora, o professor não ensina: apenas cria condições para que os alunos aprendam.

Na perspectiva de educação humanista, oportuniza-se o desenvolvimento da valorização do aluno enquanto ser humano e núcleo do processo de aprendizagem ao promover debates, produções e publicações de textos nos ambientes digitais, uma vez que essas criações serão lidas e comentadas nas mídias (fóruns, chats, links, messenger, comentários etc.) pelos colegas de classe e/ou pelo professor, além de serem devolvidas ao autor para que sejam realizadas reescrituras das produções, com o intuito de aproximá-las o mais possível dos "modelos" que circulam socialmente.

A culminância de propostas dessa configuração é a circulação das produções do gênero discursivo, momento em que o aluno percebe a funcionalidade da língua em situação real de uso e como ele pode ser o autor e peça fundamental em um processo de elaboração e criação.

Reitera-se que projetos arrojados de protagonismo estudantil com propostas textuais desse tipo, em todas as disciplinas, serão sempre bem diversificados de acordo com os gêneros e as temáticas estudadas, assim como a análise desses textos também será realizada de formas variadas: pelo professor, pelos colegas, entre pares, em grupos cooperativos e com critérios sempre estabelecidos e pontuais.

Em consonância com o último documento da Congregação para a Educação Católica (2017), faz-se necessária a humanização da educação, concebendo a pessoa como centro do processo educativo, a partir da cultura do diálogo e da construção da civilização do amor, em uma sociedade dinâmica, alegre, interdependente, diante de projetos comuns, conduzindo indivíduos ao humanismo solidário.

Em tempos em que a sociedade se torna cada vez mais robotizada e o contato interpessoal está perdendo espaço pela interação com máquinas, é imprescindível que a educação não entre nesse processo operacional e deixe de valorizar o racional. Nesse sentido, aspirando a uma educação intensa e receptiva, não se devem acolher exclusões, preconceitos, rejeições e hostilidades. Necessita-se impulsionar a diversidade de talentos, dons, capacidades e ampliar os horizontes da sala de aula a cada esfera da sociedade, na qual a educação pode suscitar interação, reciprocidade, assistência, caridade, harmonia, colaboração e paz.

\section{Considerações finais}

Urge mudar a maneira como se organiza o currículo, as metodologias, os tempos e os espaços no contexto educacional vigente. É importante que cada escola defina um plano estratégico de como conduzirá essas mudanças. A princípio, essas transformações podem acontecer de forma mais pontual, com formações e acompanhamento de professores, gestores e alunos. 
Ao enveredar nessa necessária mudança, devem-se buscar agentes e parceiros aliados, preparados e motivados a integrar os processos educativos, presenciais e virtuais. Além disso, é possível aprender com as experiências existentes e compartilhar projetos inovadores, atividades desafiantes, soluções detectadas, ideias e práticas empreendedoras.

É preciso visar sempre à contínua capacitação e formação de coordenadores, professores e alunos para usar metodologias ativas. É fundamental conceber currículos mais flexíveis e alteração na ordem tradicional de aulas (iniciam-se com atividades on-line e, em seguida, propõem-se desafios em sala de aula). Também urge mudanças mais profundas que rompam os modelos estabelecidos.

Em suma, pode-se afirmar que há muitos desafios em prol da aprendizagem significativa. Devem-se encorajar por essas transformações com estudos, análises e experiências, lidando com metodologias ativas, a partir de planejamento criterioso, objetivos bem definidos, detalhamento de atividades viáveis aos objetivos, abertura à interdisciplinaridade e uso de recursos tecnológicos e inovadores, aspectos imprescindíveis para um trabalho de excelência em uma perspectiva de educação humanista.

Enfim, a educação do novo milênio não pode permitir que se privem os direitos de crianças, adolescentes, jovens e adultos de se posicionarem, de lutarem por uma vida mais digna e justa, de serem protagonistas em sua formação. Como afirma Freire (2003), todo ato educativo é um ato político, por isso o educador, consciente de seu papel político-social, precisa permitir, em sua prática, a liberdade intelectual, promover a autonomia e o pluralismo de pensamentos, além de tentar, com sua pedagogia, libertar seus alunos da ignorância, do preconceito, do capricho, da alienação e das falsas consciências, buscando desenvolver as potencialidades humanas de cada um. Isso é humanismo e é disso que a sociedade precisa.

Recebido: 15/09/2017

Revisado pelo autor: 16/10/2017 Aceito para publicação: 25/10/2017

\section{Notas}

1 Mestrado em Linguística pelo Instituto de Letras e Linguística da Universidade Federal de Uberlândia (UFU) (2005). Graduação em Letras pela UFU (2000). Graduação em Pedagogia pela Unicoimbra/Faculdade Intervale (2016). Extensão em Novas Tecnologias de Ensino/Aprendizagem Cooperativa. Professora da Escola Salesiana - Instituto Teresa Valsé, Uberlândia/MG. Formadora da rede municipal e da rede salesiana. Elaboradora participante das Diretrizes Pedagógico-Evangelizadoras da Rede Salesiana Brasil de Escolas. E-mail: tatianeamaciel@gmail.com.br

2 Conforme Dolz, Noverraz e Schneuwly (2004, p. 97), as sequências didáticas são um “conjunto de atividades escolares organizadas, de maneira sistemática, em torno de um gênero textual oral ou escrito". 


\section{Referências}

ABREU, Maria Celia de; MASETTTO, Marcos Tarcisio. O professor universitário em aula. São Paulo: MG Editores, 1990.

ALLAN, Luciana Maria. Educação 3.0: estamos prontos? Projeto Literacia, 3 nov. 2014. Disponível em: <https://projetoliteracia.wordpress. com/2014/11/03/educacao-3-0-estamos-prontos/ >. Acesso em: 24 out. 2017.

Escola.com. Como novas tecnologias estão transformando a educação na prática. Barueri: Figurati, 2015.

ANTUNES, Irandé. Aula de português: encontro e interação. São Paulo: Parábola Editorial, 2003.

ARROYO, Miguel Gonzales. Ofício de mestre: imagens e auto-imagens. Petrópolis: Vozes, 2000.

BAKHTIN, Mikhail. Estética da criação verbal. São Paulo: Martins Fontes, 1992.

Os gêneros do discurso. In: Estética da criação verbal. São Paulo: Martins Fontes, 1997.

BARBOSA, Eduardo Fernando; MOURA, Dácio Guimarães. Metodologias ativas de aprendizagem na Educação Profissional e Tecnológica. Boletim Técnico do SENAC, Rio de Janeiro, v. 39, n. 2, p. 48-67, maio/ago. 2013.

BASTOS, Celso de Cunha. Metodologias Ativas. Educação e Medicina, 24 fev. 2006. Disponível em: <http://educacaoemedicina.blogspot.com.br/2006/02/ metodologias-ativas.html>. Acesso em: 16 out. 2017.

BERBEL, Neusi Aparecida Neves. A metodologia da problematização e os ensinamentos de Paulo Freire: uma relação mais que perfeita. In: (Org.).

Metodologia da problematização: fundamentos e aplicações. Londrina: Eduel, 1999. p. 1-28.

. As metodologias ativas e a promoção da autonomia de estudantes. Semina: Ciências Sociais e Humanas, Londrina, v. 32, n. 1, p. 25-40, jan./jun. 2011. BRASIL. Parâmetros Curriculares Nacionais (PCNs). Introdução. Ensino Fundamental. Brasilia: MEC/SEF, 1998a.

Parâmetros Curriculares Nacionais (PCNs). Língua Portuguesa. Ensino Fundamental. Terceiro e quarto ciclos. Brasília: MEC/SEF, 1998b.

. Ministério da Educação e do Desporto. Conselho Nacional de Educação. Câmara da Educação Básica. Resolução CEB n. 2, de 7 abril de 1998. Institui as Diretrizes Curriculares Nacionais para o Ensino Fundamental. Diário Oficial [da] União, Brasília, DF, 15 abr. 1998c. 
. Ministério da Educação e do Desporto. Conselho Nacional de Educação. Câmara de Educação Básica. Parecer CEB n. 4, de 29 de janeiro de 1998. Diretrizes Curriculares Nacionais para o Ensino Fundamental. Diário Oficial [da] União, Brasília, DF, 30 mar. 1998d.

. Parâmetros Curriculares Nacionais (PCNs). Ensino Médio. Brasília: MEC, 2000.

CÂMARA, Maria Lucia Botelho. Interdisciplinaridade e formação de professores na UCG: uma experiência em construção. 1999. Dissertação (Mestrado em Educação) - Faculdade de Educação, UnB, Brasília, 1999.

CARVALHO NETO, Cassiano Zeferino. Educação digital: paradigmas, tecnologias e complexmedia dedicada à gestão do conhecimento. 2011. Tese (Doutorado em Educação) - Universidade Federal de Santa Catarina, Florianopólis, 2011.

. A Manufatura Avançada, a formação de engenheiros e a Educação 4.0. ECO Educacional, 31 ago. 2017. Disponível em: <https://ecoeducacional. com.br/blog/2017/08/31/manufatura-avancada-formacao-de-engenheiros-e -educacao-4-0/>. Acesso em: 24 out. 2017.

. Educação 4.0, macrovisão. ECO Educacional, 19 set. 2017. Disponível em: < https://ecoeducacional.com.br/blog/2017/09/19/principios-e-praticas-de-inovacao-em-gestao-e-docencia/>. Acesso em: 24 out. 2017.

GERALDI, João Wanderley; CITELLI, Beatriz (Coords.). Aprender e ensinar com textos de alunos. 6. ed. São Paulo: Cortez, 2004.

CYRINO, Eliana; TORALLES-PEREIRA, Maria Lucia Trabalhando com estratégias de ensino-aprendizado por descoberta na área da saúde: a problematização e a aprendizagem baseada em problemas. Cad. Saúde Pública, v. 20, n. 3, p. 780-788, 2004.

DELORS, Jacques et al. Educação: um tesouro a descobrir. Relatório para a UNESCO da Comissão Internacional sobre a Educação para o Século XXI. 6. ed. Tradução de José Carlos Eufrázio. São Paulo: Cortez, 2001.

DOCUMENTO DA CONGREGAÇÃO PARA A EDUCAÇÃO CATÓLICA. Educar ao Humanismo Solidário. Para construir uma "civilização do amor” 50 anos após a Populorum progressio. Roma, 16 abr. 2017.

DOLZ, Joaquim; NOVERRAZ, Michèle; SCHNEUWLY, Bernard. Sequências didáticas para o oral e a escrita: apresentação de um procedimento. In: DOLZ, Joaquim; SCNEUWLUY, Bernard. Gêneros orais e escritos na escola. Campinas: Mercado das Letras, 2004. p. 95-128. 
FREIRE, Paulo. Pedagogia da autonomia: saberes necessários à prática educativa. 26 ed. São Paulo: Paz e Terra, 2003.

GARIN, Eugenio. L'éducation de l'homme moderne. Paris: Fayard, 2003.

GOMES, Maria João. Blogs: um recurso e uma estratégia pedagógica. In: SIMPÓSIO INTERNACIONAL DE INFORMÁTICA EDUCATIVA, 7., 2005, Leiria, Portugal. Anais... Leiria, 2005. Disponível em: <https://repositorium. sdum.uminho.pt/bitstream/1822/4499/1/Blogs-final.pdf $>$. Acesso em: 17 out. 2017.

KLEIMAN, Angela. Oficina de leitura: teoria e prática. 8 ed. Campinas-SP: Pontes, 2001.

KOCH, Ingedore. Argumentação e linguagem. São Paulo: Cortez, 1993.

Desvendando os segredos do texto. 2 ed. São Paulo: Cortez, 2002a.

O texto e a construção dos sentidos. São Paulo: Contexto, 2002b.

. A inter-ação pela linguagem. São Paulo: Cortez, 2003.

LAJOLO, Marisa. Do mundo da leitura para a leitura do mundo. 3 ed. São Paulo: Ática, 1997.

LÉVY, Pierre. Cibercultura. São Paulo: Editora 34, 1999.

LOPES-ROSSI, Maria Aparecida (Org.). Gêneros discursivos no ensino da leitura e produção de textos. Taubaté: Cabral Editora e Livraria Universitária, 2002.

MARCUSCHI, Luiz Antônio. Gêneros textuais: definição e funcionalidade. In: DIONISIO, Angela Paiva et al. (Orgs.). Gêneros textuais \& ensino. 2. ed. Rio de Janeiro: Lucerna, 2003.

. Leitura e compreensão de texto falado e escrito como ato individual de uma prática social. In ZILBERMAN, Regina; SILVA, Ezequiel (Orgs.). Leitura: perspectivas interdisciplinares. São Paulo: Ática, 2005.

Produção textual, análise de gêneros e compreensão. São Paulo: Parábola, 2008.

MIZUKAMI, Maria da Graça. Ensino: as abordagens do processo. São Paulo: Editora EPU, 1986.

MORAN, José Manuel. A educação que desejamos: novos desafios e como chegar lá. 5 ed. Campinas: Papirus, 2014.

MOREIRA, Marco Antonio; MASINI, Elcie Salzano. Aprendizagem significativa: a teoria de David Ausubel. São Paulo: Editora Moraes, 1982. 
PARANÁ. SECRETARIA DE ESTADO DA EDUCAÇÃO. Superintendência da Educação. Diretrizes Curriculares de Língua Portuguesa para a Educação Básica. Curitiba: Imprensa Oficial, 2006.

ROCHA, Henrique; LEMOS, Washington. Metodologias ativas: do que estamos falando? Base conceitual e relato de pesquisa em andamento. In: SIMPÓSIO PEDAGÓGICO E PESQUISAS EM EDUCAÇÃO, 9., 2014, Resende. Anais... Resende: AEDB, 2014.

SANCHO GIL, Juanna María et al. Tecnologias para transformar a educação. Porto Alegre: Artmed, 2006.

SANTOS, Carlos Alberto Moreira dos. O uso de metodologias ativas de aprendizagem a partir de uma perspectiva interdisciplinar. In: CONGRESSO NACIONAL DE EDUCAÇẪ, 12., 2015, Curitiba. Anais... Curitiba: PUC, 2015. Disponível em: <http://educere.bruc.com.br/arquivo/pdf2015/20543_10759. pdf>. Acesso em: 17 out. 2017.

SOARES, Magda. Letramento: um tema em três gêneros. Belo Horizonte: Autêntica, 1999.

VYGOTSKY, Lev. Pensamento e linguagem. São Paulo: Martins Fontes, 1989.

ZILBERMAN, Regina (Org.). Leitura em crise na escola. 11ed. Porto Alegre: Mercado Aberto, 1993. 